\title{
Epithelial reticular Cells of Egyptian Water buffalo (Bosbubalis)
}

\author{
Roshdy, $\mathrm{K}^{1}$.and Derbalah, $\mathrm{A}^{2}$.

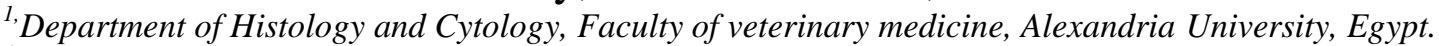 \\ ${ }_{2}^{2}$,Department of Histology and Cytology, Faculty of veterinary medicine, Alexandria University Egypt,
}

\begin{abstract}
Thymus obtained from10 clinically healthy Egyptian water male buffalo (Bosbubalis). Their ages ranged between 2 to 3 years old. The thymus of Egyptian water buffalo was divided by septa into many lobules; each lobule had outer, cortex and inner medulla. The epithelial reticular cells were classified according to their staining affinity, morphology and position into 4 types, three were found within the cortex and one in the medulla. In cortex epithelia reticular cells type I (ER 1) had elongated nucleus of irregular or triangular shape with marginal heterochromatin clumps along the nuclear membrane. Epithelial reticular cells type II(ER II) were irregular in shape with pale stained cytoplasm and the nuclei were large and spherical having euchromatin. Epithial reticular cells type III(ERIII) were characterized by large nucleus of irregular shape having marginal heterochromatin. In medulla epithelial reticular (ER) cells of type IV, they were the largest epithelial cells forming the unique elements of the thymic medulla (Hassall's corpuscles)). Cytoplasm was occupied by many small vacuoles, very large vacuole appeared in the cytoplasm pushed the nucleus into one side.
\end{abstract}

Keywords: Egyptian water Buffalo, Thymus, epithelial reticular cells.

\section{Introduction}

The Buffalo population in Egypt exhibited $47 \%$ of the total population in comparison to cattle [1]. The buffalo population in Egypt had increased from 325,0000 heads in 1993 to about 4,200,000 heads in 2013. This increasing was as a result of high demand for buffalo products such as milk, cheese and butter [2]. Because cattle and water buffalo were differently respond to certain infectious agents and existed in very different environments, it was likely that the water buffalo would not be affected by vaccines and management regimens designed for cattle[3]. It was important to characterize the immune system of the water buffalo and detect the changes in the immune response that account for the development of protective immunity[4].

The thymus considered as one of the primary central organ of the lymphoid system. They were increased in their size until age of puberty, after that they decreased in their size [5],[6].The human thymus contained six types of epithelial reticular cells; some of them formed a cyto-reticulum that subdivided the thymus into small lymphocytes-filled compartments essential for development of immunocompetent $T$ cells [7]. In young rat the thymic cortex was heavily populated by developing $\mathrm{T}$ cells along with a smaller proportion of associated epithelial cells,In the medulla larger mature $\mathrm{T}$ cells were present where epithelial and other cell types were more abundant[8].In camel, [9] classified the epithelial reticular cells with the thymus into 6 distinct types, three types were found in the cortex and three types were found in the medulla Therefore, in the present study below, we have attempted to describe the different types of the epithelial reticular cells distributed within the Egyptian water buffalo thymus To evaluate the immune responses of water buffalo to infectious agents and potential vaccines.

\section{Animals}

\section{Materials And Methods}

This study was carried out on 10 thymus obtained from healthy male Egyptian water buffalo. Their ages ranged 2 to 3 years old .Specimens were taken from different parts of thymus (peripheries and center) and fixed in $10 \%$ neutral buffered formalin for 48 hours then used for routine histological study.

\section{Light microscopy}

The specimens were routinely processed in the neutral buffered formalin, dehydrated in ascending grades of ethyl alcohol. Specimens were cleared in xylene and embedded in three changes of paraffin. $5 \mu \mathrm{m}$ thick sections were prepared, mounted on slides and stained with Harris haematoxylin and eosin[10].

\section{Electron microscopy}

Pieces of $1 \mathrm{~mm}^{3}$ were taken from the thymus from the same regions were taken for routine histological study then fixed immediately in the 4FIG (2\% formaldehyde, $1.25 \%$ gluteraldehyde in $0.1 \mathrm{M}$ sodium cacoddylate, $\mathrm{PH} 7.2)$ and stored at $4^{\circ} \mathrm{C}[11]$ Following postfixation in $1 \%$ OsO4 solution in phosphate buffer $(\mathrm{Ph}$ 7.4). The material was embedded in epoxy araldite[12].Then the ultrathin sections $(60-100 \mathrm{nms})$ were cut by a diamond knife LKB ultramicrtome then they were stained with uranyl acetate followed by lead citrate and with 
Joel transmission electron microscope working at $100 \mathrm{cx} 80 \mathrm{KVS}$.

\section{Results}

The thymus of Egyptian water buffalo was divided by septa into many lobules; each lobule had outer dark area called, cortex and inner slightly stained area called, medulla "Fig. 1". The epithelial reticular cells were classified according to their staining affinity, morphology and position into:4 types were found within the cortex and medulla.

\section{Epithelial reticular cells in the cortex}

Epithelial reticular (ER) cells of type I. They had poorly stained cytoplasm and lightly stained nuclei of elongated to oval shape with some chromatin clumps along the inner surface of the nuclear membrane "Fig. 2". By transmission electron microscopy, these cells had elongated nucleus of irregular or triangular shape with marginal heterochromatin clumps along the nuclear membrane. The cytoplasm contained empty vacuoles of variable sizes and polyribosomes "Fig.3".Epithial reticular (ER) cells of type II. They were distributed among the cortical lymphocytes the outer cortical zone. They had irregular outlines with pale stained cytoplasm and the nuclei were large and spherical in shape "Fig. 4". By electron microscopy, these cells had large spherical nucleus having abundant euchromatin. The cytoplasm contained many vacuoles of variable sizes and contained amorphous secretion and polyribosmes"Fig. 5".

Epithelial reticular (ER) cells of type III .They had irregular outlines and darkly stained indented nuclei "Fig. 6". By electron microscopy, these cells were characterized by an elongated nucleus of irregular shape having marginal heterochromatin, their cytoplasm contained vacuoles of variable sizes and ribosomes. Desmosomes were found between adjacent cell "Fig. 7".

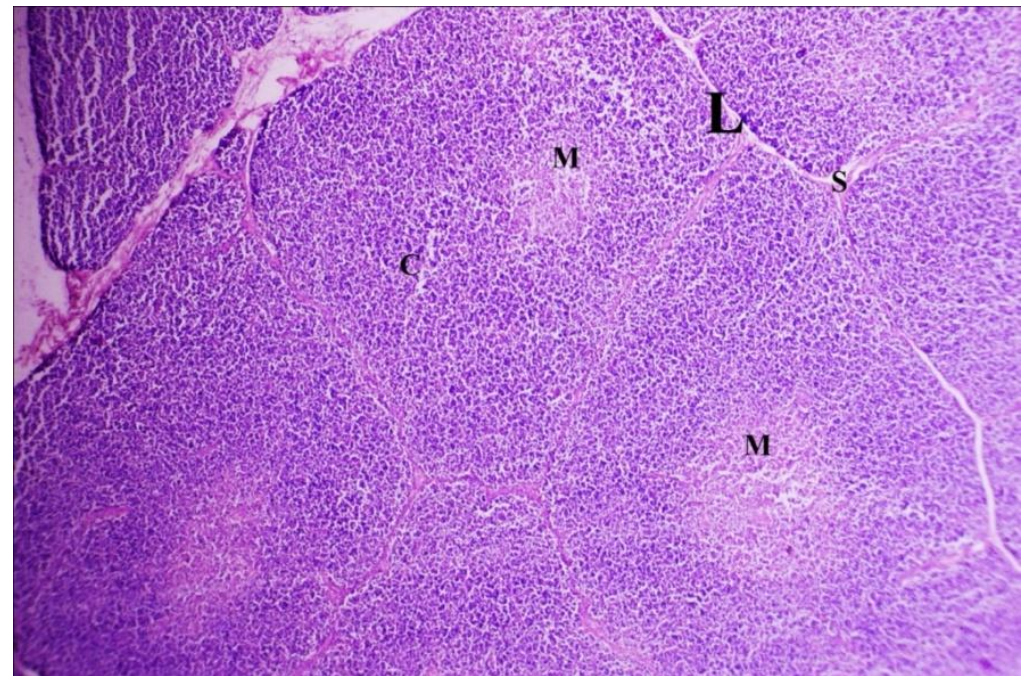

Fig. 1:-Light photo micrograph of buffalo thymus showing septa (S), lobules (L), cortex (C) and, medulla (M). Micro.Mag.x 100 Stain H \& E

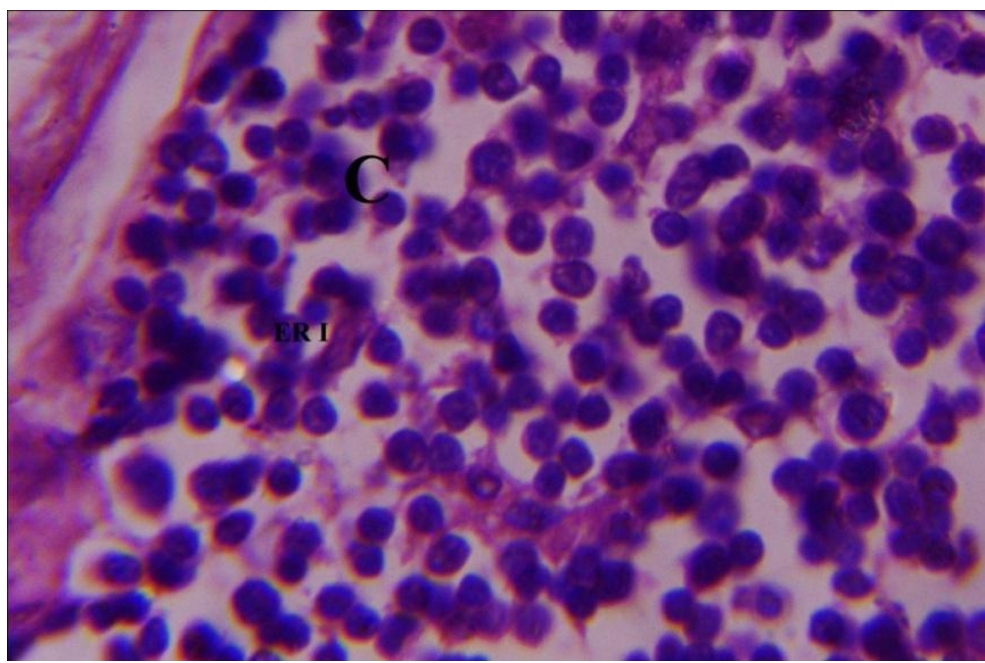

Fig. 2.Light photo micrograph of buffalo thymus showing cortex (C) and epithelial reticular cell type I(ER1). 


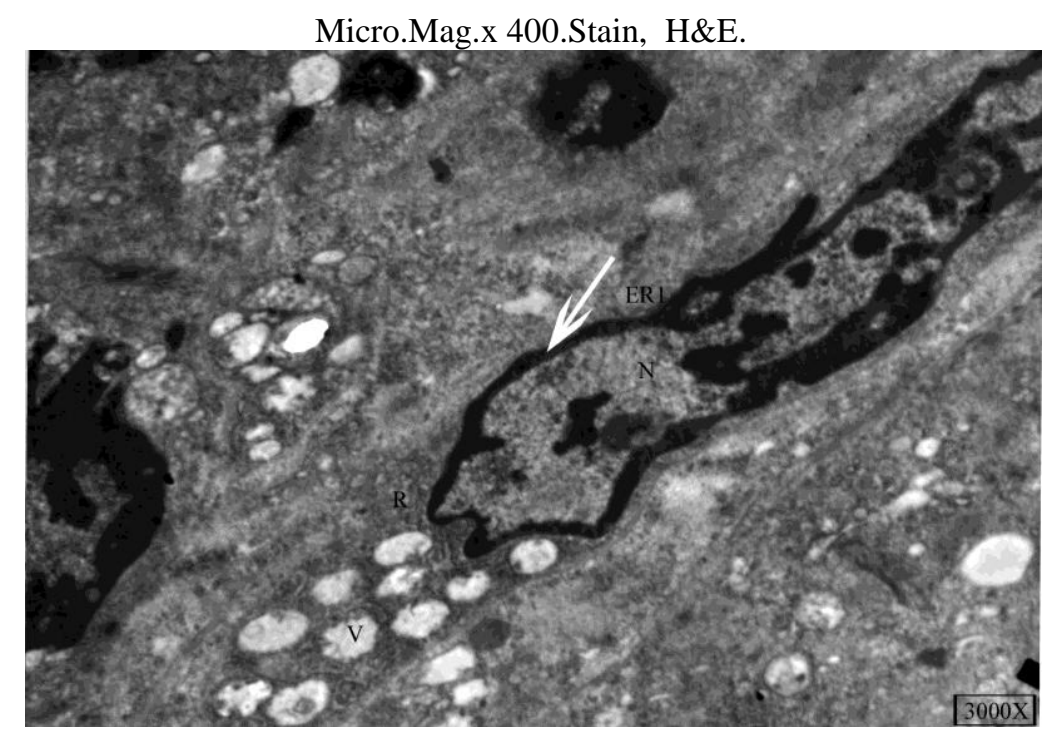

Fig. 3.Transmission electron micrograph of buffalo thymus depicting epithelial reticular type I (ER1), nucleus $(\mathrm{N})$, heterochromatin (arrow), vacuoles (V) and polyribosomes (R).X3000.

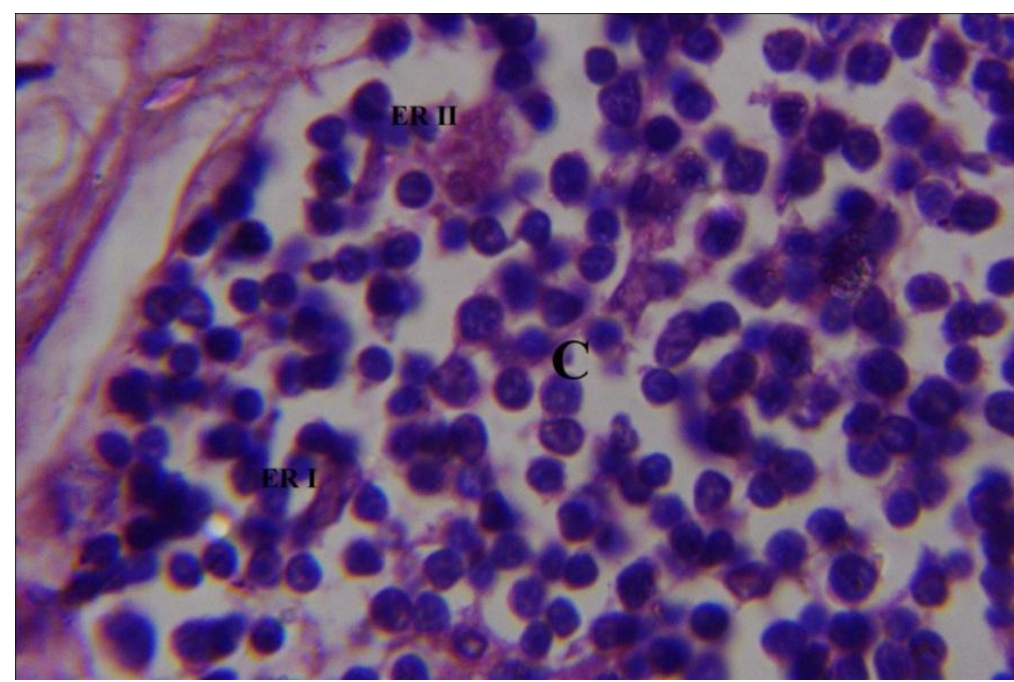

Fig. 4. Another light photomicrograph showing epithelial reticular type I(ER1) cell , epithelial reticular type II (ERII) and cortex (C).Micro. Mag. x400. Stain H \& E.

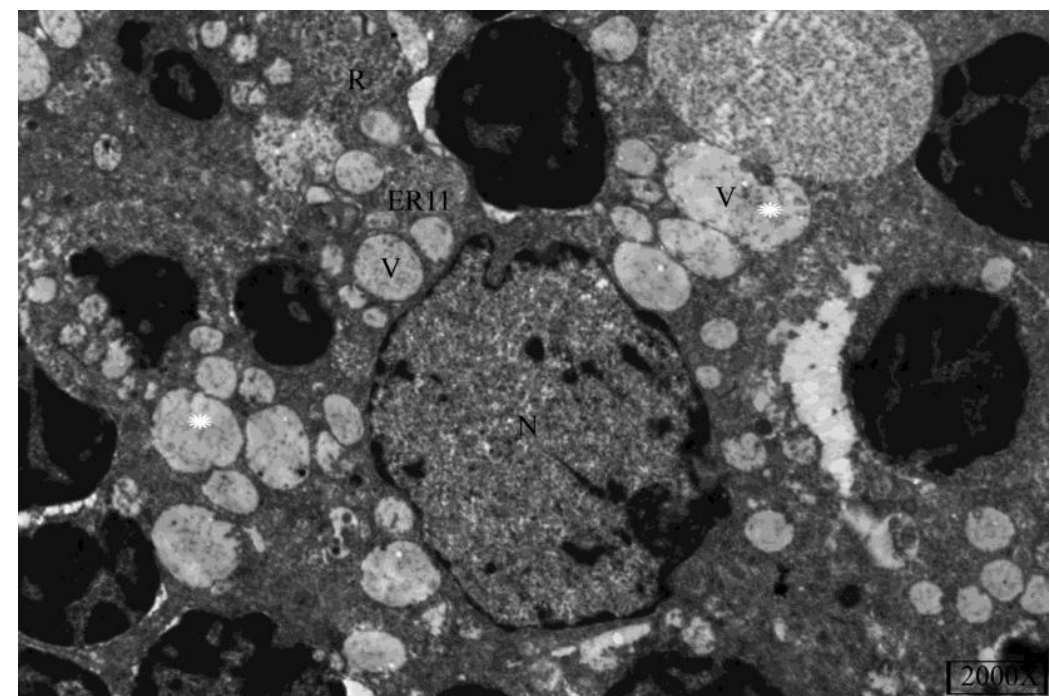

Fig. 5.Another electron micrograph depicting epithelial reticular type II (ER11), nucleus (N).,vacuoles (V) amorphous content (astrik) and Polyribosmes (R).x2000. 


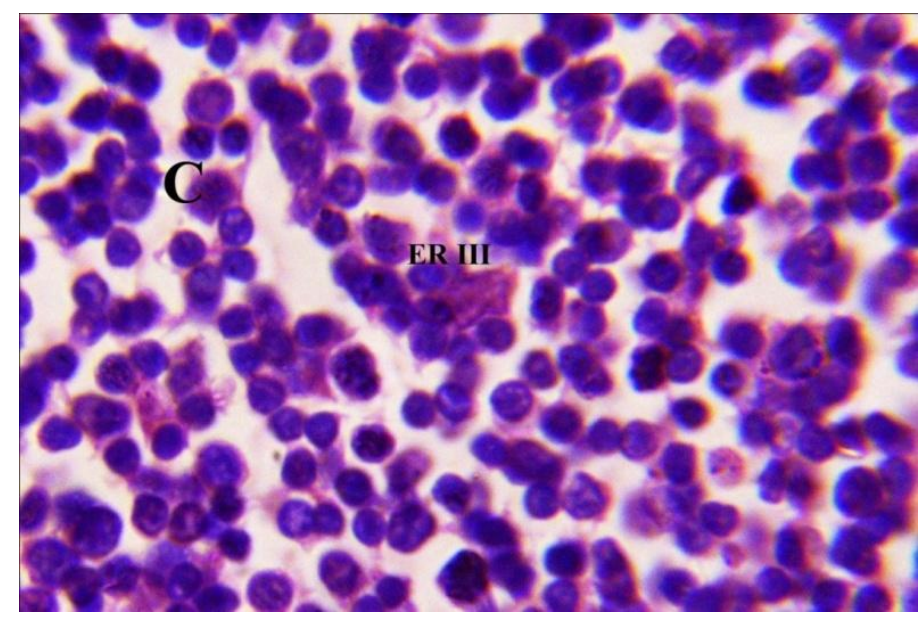

Fig. 6.light photomicrograph showing mid cortex (C) of buffalo thymus and epithelial reticular type cell type III (ER111).Micro.Mag.x 400.Stain H \& E.

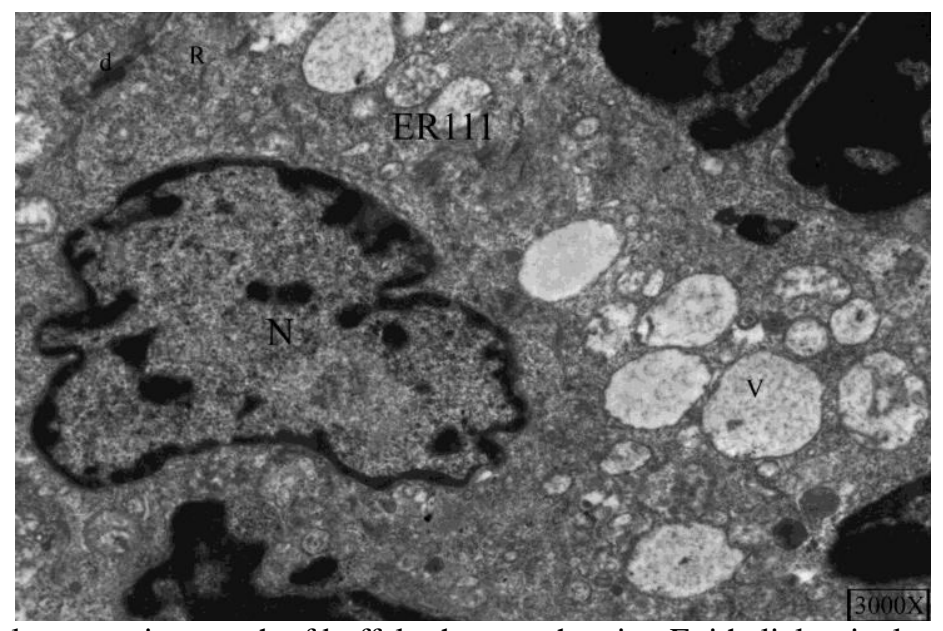

Fig.7.Transmission electron micrograph of buffalo thymus showing Epithelial reticular cell type III(ER111) ,nucleus $(\mathrm{N})$, polyribosomes $(\mathrm{R})$, desmosomes $(\mathrm{d})$ and many vacuoles $(\mathrm{V}) . \mathrm{x} 3000$.

\section{Epithelial reticular cells in the medulla}

Epithelial reticular (ER) cells of typeIV.They were the largest epithelial cells forming the unique elements of the thymic medulla (Hassall's corpuscles)"Fig. 8,9". The nucleus was condensed and cytoplasm contained many small vacuoles were containing amorphous material very large vacuole appeared in the cytoplasm pushed the nucleus into one side "Fig. 10".

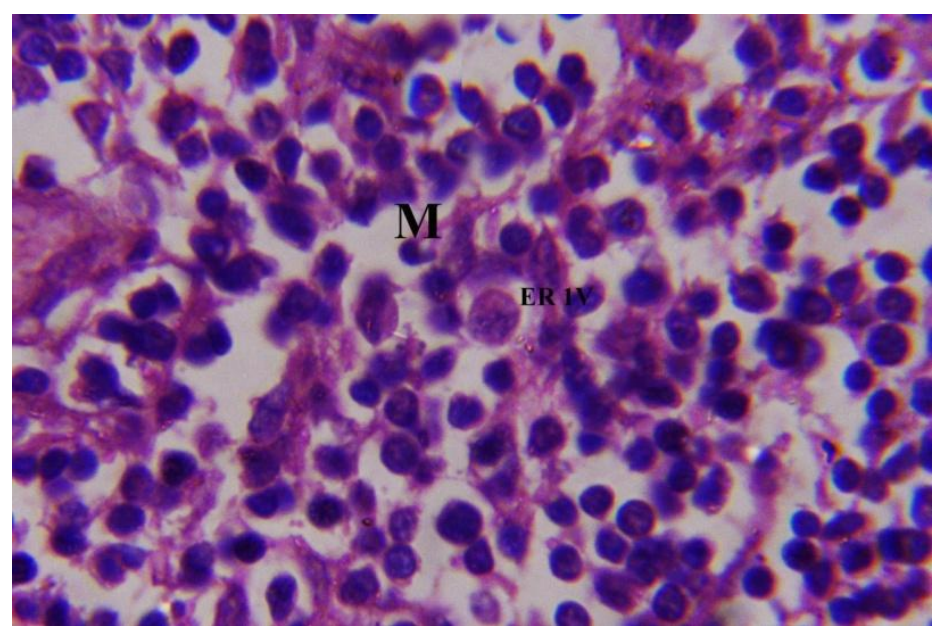

Fig.8.light photomicrograph of Medulla(M) showing epithelial reticular cells type 1V.(ER 1V).Micro.Mag.x400.StainH\&E. . 


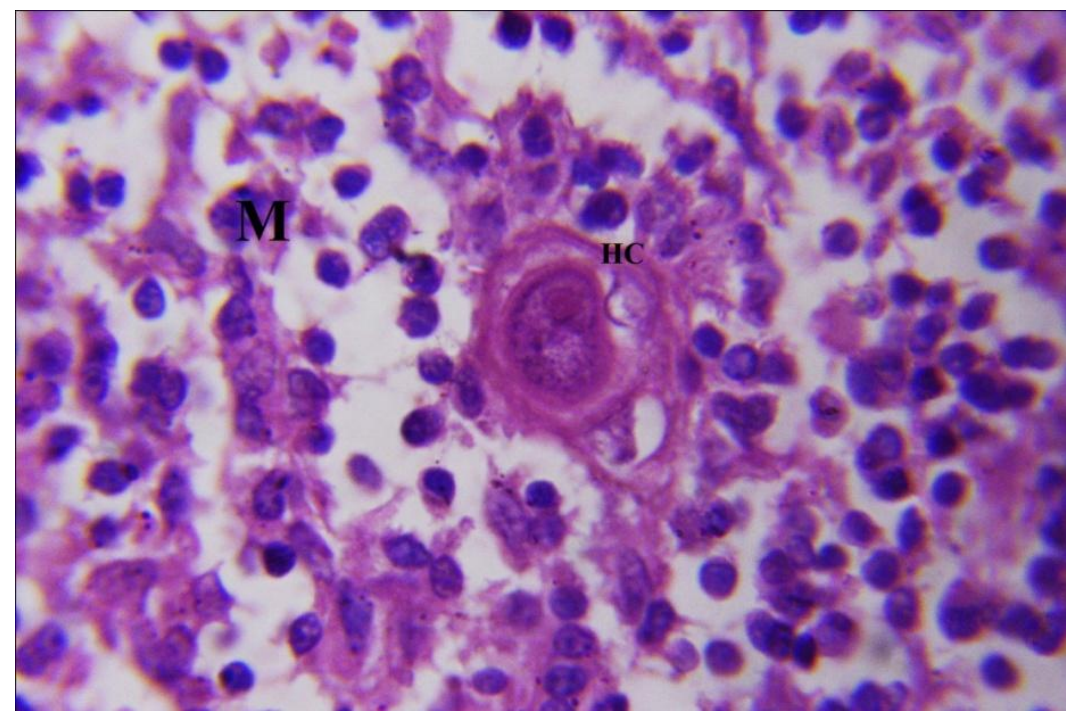

Fig. 9.Lightphotomicrograph of Medulla (M) depicting Hassall's corpuscle (HC) Micro.Mag.x400.StainH\&E.

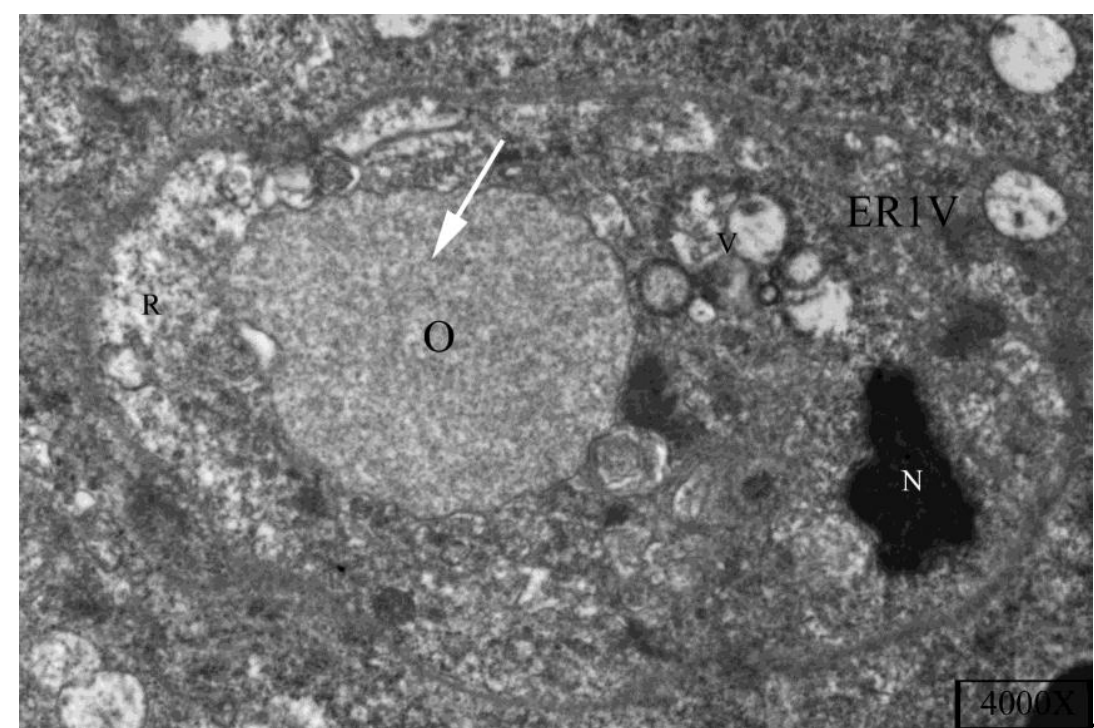

Fig. 10.Transmission electron micrograph of medulla of buffalo thymus showing Epithelial reticular cell type $1 \mathrm{~V}($ ER1V), condensed nucleus $(\mathrm{N})$, small vacuoles $(\mathrm{V})$, large vacuole(o)containing amorphous material

(arrow) and ribosomes .x 4000

\section{Discussion}

The epithelial reticular cells were classified according to their staining affinity, morphology and position into: 6 types were found within the cortex and medulla .Epithelial reticular (ER) cells of type I. They had poorly stained cytoplasm, therefore the Egyptian water buffalo was similar to human, [13]. The cytoplasm of these cells had empty vacuoles of variable sizes. Similar finding were observed in rat, [14] while reference [15] in rat found that the cytoplasm contained vacuoles filled with coarsely granular electron-dense material. Reference [13] and reference [16] found that numerous obvious pinocytotic vesicles were facing the basal lamina. Reference [9] in, camel cortical type I epithelial reticular cell had a prominent nucleolus was surrounded by clumped heterochromatin giving the nucleus a tigeroid appearance. Epithelial reticular cells type II was distributed among the cortical lymphocytes in outer cortical zone. They had large spherical nucleus and cytoplasm contained many vacuoles of variable sizes and contained amorphous secretion. In camel, [17] the most characteristic features were numerous bundles of tonofilaments in the cytoplasm with some terminating on the desmosomes, while [18] found the presence of these tonofibrils in their cytoplasm was evident for the epithelial origin of these cells. Reference [9] their cytoplasm had electron dense granules of variable size, few of them with a light rod-like core and abundant rough endoplasmic reticulum. Type III cells had irregular outlines and their cytoplasm contained many tonofilaments, vacuoles of variable sizes and ribosomes, similar findings were mentioned in human [13] in camel [9]. 
Type-IV epithelial reticular cells of human had dark cytoplasm containing spherical vacuoles with amorphous material of moderate to high electron density, [16]Similar were also reported in our study.Epithial reticular cell type- $\mathrm{V}$ was characterized by their irregular shape. Their nuclei contained more euchromatin with some marginal heterochromatin condensed along the inner surface of the nuclear membrane.Similar findings were mentioned in human [16] while,[9]in camel ,The cytoplasm had a little number of electron dense granules, empty vacuoles and bundles of tonofilaments. Epithelial reticular cell type-VI was the largest epithelial cells forming the unique elements of the thymic medulla (Hassall's corpuscles). Cytoplasm contained many small vacuoles were containing amorphous material very large vacuoles. Reference [19] classified these cells into two types hypertrophic and cystic epithelial cells, they were occupied by clusters of irregular or spherical shaped empty vacuoles and electron dense granules. The empty vacuoles had electron dense membrane with microvillus projections into the lumen of some of them.

In camel, type-VI epithelial reticular cells had two different types. a) The first type (hypertrophic epithelial cells) was large cells with electron lucent cytoplasm with euchromatic nucleus. The cytoplasm contained large sized vacuoles. b) The second type (cystic epithelial cells) formed small groups with each other and with the epithelial reticular cells either type-V or type-VI. They had large euchromatic nuclei of spherical to oval shape. The cytoplasm occupied by clusters of irregular or spherical shaped empty vacuoles and electron dense granules,[9]. All epithelial reticular cells by electron microscopy had many vacuoles with amorphous secretion and so we suggested that they had secretory function. This agree with [20] who stated that the Hassall's corpuscles of human thymus were considered to be terminal stages of the medullary epithelial cells; also the epithelial cells of the Hassall's corpuscles were active in the secretion of cytokines and growth factors.

\section{References}

[1]. Galal, S. and Elbeltagy, A., Achievement of research in the field of buffalo production in Egypt. Animal Production and Animal Science World wide. 177,2007.

[2]. FAOSTAT:- FAO Statistics Division, FAO, Rome, Italy. www.fao.org,2013.

[3]. Sharma, S. Banerjee, D. and Gautam, O. ,Anaplasmamarginale infection in Indian water buffalo (Bubalusbubalis). Indian J. Animal Health,17(3), 1978, 105- 110.

[4]. Davis, W. Larsen, R. and Monaghan, M. ,Genetic markers identified by immunogenetic methods. Am. Fisheries Soc. Symp, 7(4), 1990, 521-540.

[5]. Warwick, R. and Williamas, P, angiology. In: Gray's anatomy. 35 ${ }^{\text {th }}$ (Ed.), Long man group.1973.

[6]. Lesson, T.S. Leeson, C.R. and Paparo, A., Text atlas of histology. Part of lymphatic organ. W. B. Saunders company. Philadelphia. USA. PP. 342-346.1988.

[7]. Gartner, L.P. and Hiat, J.L,Lymphoid (immune) system. In: color text book of histology. Chapter 12. W. B. Saunders. Philadelphia, Pennsylvania. USA. pp. 285-288.2006.

[8]. Pearse,G. Normal Structure, Function and Histology of the Thymus. ToxicolPathol . 34 (5) ,2006, 504-514.

[9]. Roshdy, K. (2009), Light and electron microscopic studies on the thymus of one humped camel (Camelus dromedaries). The master degree.Faculty of veterinary medicine.Alexandria University.Egypt

[10]. Bancroft, J. GAMBLE, M, Theory and practice of histological techniques, Elsevier Health 291Sciences, 2008.

[11]. McDowell AM., Trump F. Histologic fixatives suitable for diagnostic light and electron microscopy. Archives of Pathology and Laboratory Medicine 100(6), 1976, 405-415.

[12]. Hayat M. Basic Techniques for Transmission Electron Micro scope,(2nd Ed) . Academic press, Baltimore,1986

[13]. Wijngaert, F. Kendall, M. Schuurman, H. Rademarkers, H. and Kater, L. Heterogeneity of epithelial cells in the human thymus: An ultra structural study. Cell.Tiss. Res. 237,1984, 227-237.

[14]. Halest Van, U. Light and electron microscopic study of the normal and pathological thymus of the rat. Zeitchrift fur zellforschung. 77,1967, 534-553.

[15]. Berlińska, R. Kaczmarek, E. Warchal, J. and Jaroszewski, J. Distribution of different types within the rat thymus in the Neonatal period of life.Cell.Tiss. Res. 240,1985, 473-478.

[16]. Von Gaudecker, B. Functional histology of the human thymus. Anat. Embryol., 183,(1),1991, 1 - 15.

[17]. Aly, E. Abdo, M. Algaily, S. and Prentis, P. Electron Microscopic studies on the thymus of Arabian camel (camelus Dromedaries). Anat. Anz. Jena. 167(2), 1988, 119-127.

[18]. Kessel, R.G. Lymphatic tissue. In: Basic medical histology. Chapter 10.Oxford university press, oxford, New York. 1988, Pp. 200207.

[19]. Mandel, T. Differentiation of epithelial cells in the mouse thymus.Z. Zellforsch. 106(5),1970, 468-501.

[20]. Nishio, H. Matsui, K. Tsuji, H. Tamura, A. and Suzuki, K.: Immuno-localization of mitogen activated protein kinase signaling pathway in Hassall's corpuscles of the human thymus. Acta-histochem. 103(1),2001, 89-98. 